\title{
CHANGES IN RETINAL NERVE FIBER LAYER THICKNESS ON HEIDELBERG RETINAL TOMOGRAPHY IN PATIENTS OF PRIMARY OPEN ANGLE GLAUCOMA AFTER TRABECULECTOMY VERSUS ANTI GLAUCOMA MEDICATION
}

\section{Asima Rafique', Asad Aslam Khan', Muhammad Shaheer ${ }^{2 凶}$}

\begin{abstract}
OBJECTIVE: To compare the retinal nerve fiber layer (RNFL) thickness changes in patients of primary open-angle glaucoma after trabeculectomy versus antiglaucoma medication.

METHODS: This quasi-experimental study was conducted from $10^{\text {th }}$ February, 2017 to $28^{\text {th }}$ February, 2018 on 60 patients presenting to the Institute of Ophthalmology, Mayo Hospital, Lahore, Pakistan using non-probability consecutive sampling. Patients were assigned to two equal groups: group $A$ $(n=30)$ patients underwent trabeculectomy while group $B(n=30)$ patients were put on anti-glaucoma medication. Pre-treatment and three months posttreatment RNFL thickness was recorded and then analyzed using SPPSv. I8.0.

RESULTS: Out of 60 patients, Group A $(n=30)$ had $14(46.71 \%)$ males and 16 (53.31\%) females, while Group B $(n=30)$ had $16(53.31 \%)$ males and 14 $(46.7 I \%)$ females. The mean age was $55.901 \pm 4.22 I$ and $55.43 I \pm 3.97 I$ years in Group A and Group B respectively $(\mathrm{p}=0.66 \mathrm{I})$. In age group, $16(53.31 \%)$ each in Group A and Group B were $<55$ years. Hypertensive status showed $9(30.01 \%)$ and $5(16.71 \%)$ hypertensive patients in Group A and Group B respectively. Mean change in RNFL thickness was $0.028 \pm 0.012 \mu$ and $0.013 \pm 0.007 \mu$ in Group $A$ and Group B respectively $(p=<0.00 \mathrm{I})$. Pre and post-treatment (pre:post) RNFL thickness $(\mu)$ in males, females, hypertensive, non-hypertensive, age $<55$ years, and age $\geq 55$ years was $0.20 \mathrm{I} \pm 0.175 \mu: 0.226 \pm 0.155$, $0.205 \pm 0.159: 0.233 \pm 0.019,0.193 \pm 0.015: 0.223 \pm 0.013$, $0.206 \pm 0.015: 0.233 \pm 0.018,0.208 \pm 0.015: 0.232 \pm 0.021$, and $0.196 \pm 0.016: 0.228 \pm 0.015$ for Group $A$ and $0.211 \pm 0.018: 0.224 \pm 0.019$, $0.20| \pm 0.0| 5: 0.2|5 \pm 0.0| 4,0.2|4 \pm 0.0| 5: 0.226 \pm 0.0 \mid 6$, $0.205 \pm 0.018: 0.218 \pm 0.017,0.206 \pm 0.017: 0.219 \pm 0.015$, and $0.209 \pm 0.019: 0.221 \pm 0.020$ for group B respectively.
\end{abstract}

CONCLUSION: Trabeculectomy increases thickness of retinal nerve fiber layer more than anti glaucoma medication.

KEY WORDS: Retina (MeSH); Glaucoma, Open-Angle (MeSH); Trabeculectomy (MeSH); Nerve Fibers (MeSH); Heidelberg Retinal Tomography (Non-MeSH).

THIS ARTICLE MAY BE CITED AS: Rafique A, Khan AA, Shaheer M. Changes in retinal nerve fiber layer thickness on Heidelberg retinal tomography in patients of primary open angle glaucoma after trabeculectomy versus anti glaucoma medication. Khyber Med Univ J 2020; I 2(3):2 I I-5. DOI: 10.35845/kmuj.2020.20062.

\section{INTRODUCTION}

G laucoma is an irreversible and progressive optic neuropathy causing structural changes to the optic nerve head $(\mathrm{ONH})$ and retinal nerve fiber layer (RNFL) along with loss of visual field, the most important risk factor for which is raised Intraocular pressure (IOP). ${ }^{1,2}$ RNFL changes always precede changes in $\mathrm{ONH}$ parameters and visual field defects. ${ }^{3}$ One of the most important cause of permanent blindness around the globe is glaucoma.
I. Institute of Ophthalmology, Mayo Hospital, Lahore, Pakistan.

2. Department of Ophthalmology, Post Graduate Medical Institute, Lahore, Pakistan. Email『: mshaheer212@gmail.com Contact \#: +92-333-6568618

Date Submitted: February 02, 2020 Date Revised: July 07, 2020 Date Accepted: July 10,2020

The pooled global prevalence of primary open angle glaucoma (POAG) is estimated to be $3.54 \% .^{4}$ In addition, Asia account for $53.4 \%$ of worldwide POAG cases. ${ }^{5}$ Glaucoma damage once done is permanent, it cannot be reversed. The end point of managing glaucoma is to help prevent the further loss of RNFL. Using medication, IOP is lowered either by reducing the amount of fluid produced in the eye or by increasing the aqueous outflow. The aim of treatment is to preserve the visual field function and reduce the IOP which is enough to achieve a therapeutic goal termed the 'target IOP range'. ${ }^{6}$ Target IOP is the range of IOP on therapy that will prevent further damage and visual field loss without affecting patient's quality of life. Trabeculectomy is the surgical procedure for lowering IOP, advised when IOP remains uncontrolled by maximally tolerated anti-glaucoma therapy. Since its advent, new advancements have been made in this surgery regarding site of surgery, limbus versus fornix based flap, use of postoperative steroids, releasable sutures, argon laser suture lysis, needling and use of antimetabolites. ${ }^{8}$ Ganglion cell loss is estimated to be $40 \%$ to $50 \%$ in glaucoma before the measurements reaches statistical significance. ${ }^{9}$ RNFL analysis provides an alternative to the visual inspection of the optic nerve, neuro-retinal rim as well as a 
TABLE I: DISTRIBUTION ACCORDING TO AGE, GENDER, HYPERTENSION AND RNFL THICKNESS IN BOTH GROUPS

\begin{tabular}{|c|c|c|c|c|}
\hline \multicolumn{2}{|c|}{ Parameter } & $\begin{array}{c}\text { Group A } \\
n=30\end{array}$ & $\begin{array}{c}\text { Group B } \\
n=30\end{array}$ & P-Value \\
\hline \multicolumn{2}{|l|}{ Age (years) } & $55.90 I \pm 4.221$ & $55.43 \mathrm{I} \pm 3.97 \mathrm{I}$ & $0.661^{* *}$ \\
\hline \multicolumn{2}{|c|}{ Mean Change in RNFL ${ }^{*}$ Thickness $(\mu)$} & $0.028 \pm 0.012$ & $0.013 \pm 0.007$ & $<0.001^{*}$ \\
\hline \multirow{2}{*}{ Gender } & Male & $14(46.67 \%)$ & $16(53.33 \%)$ & \multirow{2}{*}{$0.606^{* * *}$} \\
\hline & Female & $16(53.33 \%)$ & $14(46.67 \%)$ & \\
\hline \multirow{2}{*}{ Hypertensive Status } & Hypertensive & $9(30 \%)$ & $5(16.67 \%)$ & \multirow{2}{*}{$0.222^{* * *}$} \\
\hline & Non-Hypertensive & $21(70 \%)$ & $25(83.33 \%)$ & \\
\hline \multirow{2}{*}{ Age Group (years) } & $<55$ & $16(53.33 \%)$ & $16(53.33 \%)$ & \multirow{2}{*}{$0.999^{\circ * *}$} \\
\hline & $\geq 55$ & $14(46.67 \%)$ & $14(46.67 \%)$ & \\
\hline
\end{tabular}

quantitative estimation of retinal ganglion cell axonal loss. ${ }^{10}$ Two most important tools are optical coherence tomography (OCT) and Heidelberg retinal tomography (HRT). ${ }^{11,12}$ The HRT is a $3 D$ confocal scanning laser ophthalmoscope non-invasive procedure which scans retina in 24 milliseconds 64 consecutive sequential scans, starting above the retinal surface, and then capturing parallel images at increasing depths $0-4 \mathrm{~mm}$ over an area of I 5 degree using 670 nm diode laser. ${ }^{13}$

Absence of any local literature on possible effects of glaucoma treatment modalities on RNFL and varying results in international literature was the rationale to conduct this study. The objective of this study was to compare the possible effects of anti-glaucoma medication and trabeculectomy on the thickness of RNFL as measured on HRT in patients of primary open-angle glaucoma.

\section{METHODS}

This quasi-experimental study was conducted from $10^{\text {th }}$ February, 2017 to $28^{\text {th }}$ February, 2018 after obtaining ethical approval from the Institutional Review Board of King Edward Medical University, Lahore, Pakistan. Patients presenting to the outpatient department of Mayo Hospital, Lahore were screened for inclusion and exclusion criteria. Patients $(n=60)$ between 40-70 years of age and diagnosed with primary open angle glaucoma at various stages requiring surgical or augmentation of medical therapy were selected by nonprobability consecutive sampling. Patients who were diagnosed with secondary glaucoma or any coexisting ocular pathology except for refractive errors were excluded from study. Demographic data of patients was recorded and pre-treatment RNFL thickness was measured on HRT. Among all 60 patients, 30 were assigned as Group A patients and underwent trabeculectomy while 30 were put in group $B$, which were put on antiglaucoma medication. Post treatment retinal nerve fiber layer thickness was measured on HRT after three months and findings recorded on proforma. In trabeculectomy, a fistula was created between anterior chamber of eye and subtenon space facilitating the flow of aqueous and reducing intra ocular pressure. Group B patients were started on double agent anti-glaucoma medication (Dorzolamide $\mathrm{HCl}$ \& Timolol Maleate eye drops, twice daily). The data was entered and analyzed in SPSS v. 18.0. The quantitative data like age and pre and post treatment retinal nerve fiber layer thickness were presented as mean and standard deviation. The qualitative data like gender was presented as frequency and percentage. Independent sample $T$ test was applied for comparison of mean retinal nerve thickness change in both study groups, Paired Sample T-test was used for comparison of pre- and posttreatment RNFL thickness and ChiSquare was applied for categorical variables, $\mathrm{p}$-value $\leq 0.05$ was considered significant.

\section{RESULTS}

The mean age of patients in group $A$ was $55.901 \pm 4.221$ years and in group $B$ it was $55.431 \pm 3.971$ years. In group $A$, mean change in RNFL thickness on HRT was $0.028 \pm 0.012$ microns while in group $B$ it was $0.013 \pm 0.007$ microns (Table l).

In group $\mathrm{A}$, mean change in RNFL thickness in male patients was $0.026 \pm 0.01 \mathrm{I}$ microns and in female patients it was $0.029 \pm 0.013$ microns $(p=0.595)$. Mean change in RNFL thickness in hypertensive patients was $0.030 \pm 0.012$ microns while it was $0.027 \pm 0.012$ microns in non-

TABLE II: CHANGE IN RETINAL NERVE FIBER LAYER THICKNESS IN BOTH GROUPS

\begin{tabular}{|c|c|c|c|c|c|}
\hline & \multirow[b]{2}{*}{ Variable } & \multicolumn{2}{|c|}{$\begin{array}{c}\text { Group A } \\
n=30\end{array}$} & \multicolumn{2}{|c|}{$\begin{array}{c}\text { Group B } \\
n=30\end{array}$} \\
\hline & & $\begin{array}{l}\text { Mean Change in } \\
\text { RNFL* Thickness } \\
(\mu)\end{array}$ & P-Value & $\begin{array}{l}\text { Mean Change in } \\
\text { RNFL* Thickness } \\
(\mu)\end{array}$ & P-Value \\
\hline \multirow{2}{*}{ Gender } & Male $(n=30)$ & $0.026 \pm 0.011$ & \multirow{2}{*}{0.595} & $0.013 \pm 0.007$ & \multirow{2}{*}{0.661} \\
\hline & Female $(n=30)$ & $0.029 \pm 0.013$ & & $0.014 \pm 0.006$ & \\
\hline \multirow{2}{*}{$\begin{array}{l}\text { Hypertensive } \\
\text { Status }\end{array}$} & Hypertensive $(n=14)$ & $0.030 \pm 0.012$ & \multirow{2}{*}{0.482} & $0.012 \pm 0.008$ & \multirow{2}{*}{0.714} \\
\hline & Non-Hypertensive $(n=46)$ & $0.027 \pm 0.012$ & & $0.013 \pm 0.006$ & \\
\hline \multirow{2}{*}{$\begin{array}{l}\text { Age Group } \\
\text { (years) }\end{array}$} & $<55(\mathrm{n}=30)$ & $0.024 \pm 0.013$ & \multirow{2}{*}{0.047} & $0.013 \pm 0.007$ & \multirow{2}{*}{0.913} \\
\hline & $\geq 55(n=30)$ & $0.032 \pm 0.009$ & & $0.013 \pm 0.006$ & \\
\hline
\end{tabular}

*Retinal Nerve Fiber Layer; **Independent sample T-test. 
TABLE III: PRE AND POST-OPERATIVE RETINAL NERVE FIBER LAYER THICKNESS PROFILES IN BOTH GROUPS

\begin{tabular}{|c|c|c|c|c|c|c|}
\hline \multirow[b]{2}{*}{ Variable } & \multicolumn{3}{|c|}{$\begin{array}{c}\text { Group A } \\
(n=30)\end{array}$} & \multicolumn{3}{|c|}{$\begin{array}{c}\text { Group B } \\
(n=30)\end{array}$} \\
\hline & $\begin{array}{c}\text { Pre-Treatment } \\
\text { RNFL* Thickness } \\
(\mu)\end{array}$ & $\begin{array}{l}\text { Post-Treatment } \\
\text { RNFL* Thickness } \\
(\mu)\end{array}$ & P-value** & $\begin{array}{l}\text { Pre-Treatment } \\
\text { RNFL* Thickness } \\
(\mu)\end{array}$ & $\begin{array}{c}\text { Post-Treatment } \\
\text { RNFL* Thickness } \\
(\mu)\end{array}$ & P-value** \\
\hline Male $(n=30)$ & $0.201 \pm 0.175$ & $0.226 \pm 0.155$ & $<0.001$ & $0.211 \pm 0.018$ & $0.224 \pm 0.019$ & $<0.001$ \\
\hline Female $(n=30)$ & $0.205 \pm 0.159$ & $0.233 \pm 0.019$ & $<0.001$ & $0.201 \pm 0.015$ & $0.215 \pm 0.014$ & $<0.001$ \\
\hline Hypertensive $(n=14)$ & $0.193 \pm 0.015$ & $0.223 \pm 0.013$ & $<0.001$ & $0.214 \pm 0.015$ & $0.226 \pm 0.016$ & 0.099 \\
\hline Non-Hypertensive $(n=46)$ & $0.206 \pm 0.015$ & $0.233 \pm 0.018$ & $<0.001$ & $0.205 \pm 0.018$ & $0.218 \pm 0.017$ & $<0.001$ \\
\hline Aged below 55 Years $(n=30)$ & $0.208 \pm 0.015$ & $0.232 \pm 0.021$ & $<0.001$ & $0.206 \pm 0.017$ & $0.219 \pm 0.015$ & $<0.001$ \\
\hline Aged 55 Years or above $(n=30)$ & $0.196 \pm 0.016$ & $0.228 \pm 0.015$ & $<0.001$ & $0.209 \pm 0.019$ & $0.221 \pm 0.020$ & $<0.001$ \\
\hline
\end{tabular}

hypertensive patients $(p=0.482)$. The mean change in RNFL thickness in those aging below 55 years was $0.024 \pm 0.013$ microns and it was $0.032 \pm 0.009$ microns in those aging 55 years or above (Table II). In group B, mean change in RNFL thickness was $0.013 \pm 0.007$ microns in male patients while it was $0.014 \pm 0.006$ microns in female patients $(p=0.66 \mathrm{I})$. In hypertensive patients, mean change in RNFL thickness in hypertensive patients was $0.012 \pm 0.008$ microns while in nonhypertensive patients it was $0.013 \pm 0.006$ microns $(p=0.7 / 4)$. Mean change in RNFL thickness in those younger than 55 years was $0.013 \pm 0.007$ microns while it was $0.013 \pm 0.006$ microns in those aging $\geq 55$ years $(p=0.913)$ (Table II). The pre- and post-treatment RNFL thickness in both groups as per gender, hypertensive status and age group has been explained in Table III.

\section{DISCUSSION}

The above results showed that retinal nerve fiber layer thickness increases in response to treatment of glaucoma whether surgical or medical. However, the increase in retinal nerve fiber layer thickness was more in patients who underwent trabeculectomy as compared to those who were on antiglaucoma medications. The increase in thickness of retinal nerve fiber layer was almost double in trabeculectomy group as compared to anti-glaucoma medication group. The increase in retinal nerve finer layer thickness was also observed in all sub groups i.e. male and female patients, hypertensive and non- hypertensive patients, patients aging 55 years or above and below 55 years of age.

Raghu $\mathrm{N}$ et al ${ }^{14}$ have studied the effect of filtration surgery on thickness of retinal nerve fiber layer. They studied II patients pre- and post-trabeculectomy. They documented a significant increase in average $(p=0.019)$ and inferior $(p=0.038)$ RNFL thickness after one week of surgery only to decrease back to pre-operative level after 3 months. However our study showed an increase in RNFL thickness at 3 months. Maneesang S, et al. ${ }^{15}$ have studied the RNFL thickness changes pre and 3 months post filtration surgery for lowering the intraocular pressure. In their study 19 patients were included in whom the average RNFL thickness decreased from $59.58 \pm 17.59$ microns to $57.19 \pm 14.97$ microns contrary to our study. The thickness in four quadrants did not change significantly.

In a study, ${ }^{16}$ researchers evaluated the changes in RNFL after lowering of intra ocular pressure either by medical or surgical means. They selected 21 patients and followed them before and after the glaucoma treatment. In their study, lowering the intra ocular pressure either medically or surgically did not affect the average RNFL thickness. Quadrant analysis also showed no noticeable change in RNFL thickness in all four quadrants.

Park and associates ${ }^{17}$ have studied the short term behavior of retinal nerve fiber layer on Heidelberg retinal tomography after glaucoma filtration surgery. They studied 13 eyes of 13 patients pre operatively and two months post operatively on Heidelberg retinal tomography. They noted that mean retinal nerve fiber layer thickness in those patients increased from $0.135 \pm 0.129$ microns preoperatively to $0.162 \pm 0.091$ microns after two months of surgery. The results of this study were synonymous with our research although the followup period was more in our study.

Yamada and colleagues ${ }^{18}$ used scanning laser polarimetry to evaluate the changes in retinal nerve fiber layer after glaucoma filteration surgery. They selected 46 eyes of 46 patients who had undergone uneventful filteration surgery resulting greater than $30 \%$ reduction of intra ocular pressure. They concluded that postoperatively the retinal nerve fiber layer thickness increased in superotemporal and inferotemporal regions and this increase was statistically significant $(\mathrm{P}<0.05)$. Present study also showed a statistically significant increase in RNFL thickness after surgical therapy.

In a study, ${ }^{19}$ researchers have studied the retinal nerve fiber layer changes on optical coherence tomography after trabeculectomy. They noted a statistically significant increase in retinal nerve fiber layer thickness after trabeculectomy $(P<0.000 \mathrm{I})$. This study showed similar results to above mentioned research although no comparisons with medical therapy were made. Quadrant wise analysis also showed a significant elevation in retinal nerve fiber layer thickness in superior, temporal and nasal segments.

Koraszewska-Matuszeuska and associates $^{20}$ have studied the changes in retinal nerve fiber layer inpatients of 
juvenile glaucoma after filtration surgery for lowering the intra ocular pressure. In their study, average RNFL thickness increased from 60.61 microns to 63.09 microns after surgery. Also average superior half thickness increased from 74. 14 microns to 78.33 microns and in inferior half it increased from 70.54 microns to 72.42 microns. Though this study was conducted on patients of juvenile glaucoma in contrast to our study population of adult onset glaucoma, the results are strikingly aligned.

Rebolleda $G^{21}$ studied the changes in retinal nerve fiber layer thickness after deep sclerectomy for lowering the intra ocular pressure. They did not found any statistically significant changes in RNFL after sclerectomy.

Our study sample size was 60 with a single followup at 3 months which is small enough to make conclusive recommendations on the effects of glaucoma therapy on thickness of retinal nerve fiber layer. However, it gives an idea on which large randomized controlled trials with longer duration and multiple follow-ups can be based for a better understanding.

\section{CONCLUSION}

Surgical management (trabeculectomy) leads to more increase in retinal nerve fiber layer thickness as compared to medical therapy.

\section{REFERENCES}

I. Weinreb RN, Aung T, Medeiros FA. The pathophysiology and treatment of glaucoma: A review. JAMA 20।4;3।I(I8): I90।-II. DOI: I0.100I /jama.2014.3192.

2. Vranka JA, Kelley MJ, Acott TS, Keller KE. Extra cellular matrix in trabecular meshwork: Intraocular pressure regulation and dysregulation in glaucoma. Exp Eye Res 2015;133:II2-25. DOI: 10. 1016/j.exer.2014.07.014.

3. Gracitelli CPB, Abe RY, Tatham AJ, Rosen PN, Zangwill LM, Boer ER et al. Association between progressive retinal nerve fiber layer loss and longitudinal changes in quality of life in glaucoma. JAMA Ophthalmol 2015; I 33(4):384-90. DOI: I0.100I/ jamaophthalmol.2014.5319.

4. Tham YC, Li X, Wong TY, Quigley HA, Aung T, Cheng CY. Global prevalence of glaucoma and projections of glaucoma burden through 2040: A systematic review and meta-analysis. Ophthalmology 20I4;12I(II):208I-90. DOI: 10. 1016/j.ophtha. 2014.05.013.

5. Kapetanakis WV, Chan MPY, Foster PJ, Cook DJ, Owen CG, Rudnicka AR. Global variations and time trends in the prevalence of primary open angle glaucoma (POAG): A systematic review and metaanalysis. $\mathrm{Br} J$ Ophthalmol 2016;100:86-93. DOI: 10.1 |36/bjophthalmol-20I5307223.

6. Schultz SK, Iverson SM, Shi W, Greenfield DS. Achieving singledigit intraocular pressure targets with filtration surgery in eyes with progressive normal tension glaucoma. J Glaucoma 2016;25 (2):217-22. DOI: 10.1097/IJG. 0000000000000145 .

7. Quaranta L, Riva I, Gerardi C, Oddone F, Floriano I, Konstas AGP. Quality of life in glaucoma: A review of the literature. Adv Therap 2016;33 (6):959-8I. DOI: I0.1007/s | 2325-0|6-0333-6.

8. Behzad A, Lin SC, Ying H, Jane K. A role for antimetabolites in glaucoma tube surgery: Current evidence and future directions. Curr Opin Ophthalmol 2016;27(2):164-9. DOI: I 0.1097/ICU.00000000 00000244 .

9. Harwerth RS, Quigley HA. Visual field defects and retinal ganglion cell losses in patients with glaucoma. Arch Ophthalmol 2006; I 24(6):8539. DOI: $10.1001 /$ archopth. I 24.6. 853.

10. Yarmohammadi A, Zangwill LM, Diniz-Filho A, Suh $M H$, Yousefi $S$, Saunders LJ, et al. Relationship between optical coherence tomography angiography vessel density and severity of visual field loss in glaucoma. Ophthalmology 20I6; I23(I2):2498-508. DOI: 10. I0I6/j.ophtha.2016.08.04I.
I I. Mendez-Hernandez C, RodriguezUna I, Rosa MG, Arribas-Pardo P, Garcia-Feijoo J. Glaucoma diagnostic capacity of optic nerve head haemoglobin measures compared with spectral domain OCT and HRT III confocal tomography. Act Ophthalmol 2016;94(7):697-704. DOI: I0.1III/aos.13050.

12. Banister K, Boachie C, Bourne R, Cook J, Burr JM, Burr JM, et al. Can automated imaging for optic disc and retinal nerve fiber layer analysis aid glaucoma detection. Ophthalmology 2016; 123(5):930-8. DOI: $10.1016 / j .0 p h$ tha.2016. 0I.04I.

13. Laura SH, Wolfgang S, Robert L, Folkert H, Anslem J, Kruse FE, et al. Confocal laser scanning tomography to predict visual field conversion in patients with ocular hypertension and early glaucoma. J Glaucoma 2016;25(4):37I-6. DOI: 10.1097/IJG.000000000000017I.

14. Raghu N, Pandav SS, Kaushik S, Ichhpujani P, Gupta A. Effect of trabeculectomy on RNFL thickness and optic disc parameters using optical coherence tomography. Eye 20|2;26(8): I|3|-7. DOI: I 0. 1038/eye.2012.1I5.

15. Maneesang $S$, Jatutong $O$, LemsomboomW. The assesment of retinal nerve fiber layer thickness changing after glaucoma surgery by Optical Coherence Tomography, Pharmongkutklao Hospital. J Med Assoc Thai 20I2;95(5):75-9.

16. Chang PT, Sekhon N, Budenz DL, Feuer WJ, Park PW, Anderson DR. Effect of lowering intraocular pressure on Optical Coherence Tomography measurement of peripapillary retinal nerve fiber layer thickness. Ophthalmology 2007; I |4(I 2):2252-8. DOI: 10. 4103/0974-620x. 127910

17. Park KH, Kim DM, Youn DH. Short term change of optic nerve head topography after trabeculectomy in adult glaucoma patients as measured by Heidelberg retinal tomograph. Korean J Ophthalmol 1997; II:I-6. DOI: I0.334I/ 
kjo.1997.II.I.I.

18. Yamada N, Tomita G, Yamamoto T, Kitazawa Y. Changes in nerve fiber layer thickness following a reduction of intraocular pressure after trabeculectomy. J Glaucoma 2000;9(5):37|-5. DOI: 10.1097/ 0006। 198-200010000-00005.

19. Aydin A, Wollstein G, Price LL, Fujimoto JG, Schumann JS. Optical coherence tomography assessment of retinal nerve fiber layer thickness changes after glaucoma surgery. Ophthalmology 2003; I 10(8): 1506II. DOI: 10.1016/S016I-6420(03) 00493-7.

20. Koraszewska-Matuszeuska B, Samochowiec-Donocik E. Evaluation of retinal nerve fiber layer thickness in eyes with juvenile glaucoma after trabeculectomy. Klin Oczna 2004; I 06(suppl 3):443-4.

21. Rebolleda G, Munoz-Negrete FJ, Noval S. Evaluation of changes in peripapillary nerve fiber layer thickness after deep sclerectomy with optical coherence tomography. Ophthalmology 2007; I 14(3):488-93. DOI: 10.1016/j.ophtha.2006.06.05I.

\section{AUTHORS' CONTRIBUTIONS}

Following authors have made substantial contributions to the manuscript as under:

AR: Conception and study design, acquisition of data, drafting the manuscript, final approval of the version to be published

AAK: Acquisition of data, critical review, final approval of the version to be published

MS: Analysis and interpretation of data, drafting the manuscript, final approval of the version to be published

Authors agree to be accountable for all aspects of the work in ensuring that questions related to the accuracy or integrity of any part of the work are appropriately investigated and resolved.

CONFLICT OF INTEREST

Authors declared no conflict of interest GRANT SUPPORT AND FINANCIAL DISCLOSURE NIL
DATA SHARING STATEMENT

The data that support the findings of this study are available from the corresponding author upon reasonable request

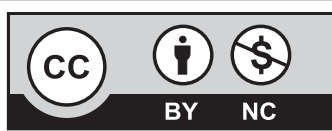

This is an Open Access article distributed under the terms of the Creative Commons Attribution-Non Commercial 2.0 Generic License.

KMUJ web address: www.kmuj.kmu.edu.pk

Email address: kmuj@kmu.edu.pk 